\title{
RANCANG BANGUN SISTEM GERBANG KEAMANAN BERBASIS RFID ID-12 PADA PERPUSTAKAAN
}

\author{
Rendy Oktavianus, Agus Trisanto, Ph.D., Meizano A Muhammad, M.T., Helmy Fitriawan, M.Sc. \\ Jurusan Teknik Elektro Universitas Lampung \\ Jl. Prof. Sumantri Brojonegoro No. 1 Bandar Lampung 35145 \\ oktavianusrendy@gmail.com
}

\begin{abstract}
Abstrak
Radio Frequency identification (RFID) merupakan sebuah metode identifikasi menggunakan sarana yang disebut tag RFID atau transponder untuk menyimpan dan mengambil data. Teknologi RFID dalam bidang keamanan menarik untuk dikembangkan. Salah satunya adalah aplikasi pada sistem gerbang keamanan perpustakaan. Sistem gerbang keamanan ini dirancang untuk mendeteksi buku yang masuk dan keluar perpustakaan secara real time melalui aplikasi web.

Sistem gerbang keamanan berbasis RFID ID-12 dibangun menggunakan arduino. Arduino digunakan untuk mentransfer data yang diperoleh reader RFID dalam komputer dengan komunikasi serial. Penambahan antena eksternal dilakukan guna menyimpan perangkat elektronik pada tempat yang aman. Antena eksternal digunakan bersamaan dengan penguat kelas C. Penguatan kelas $\mathrm{C}$ bertujuan untuk mengurangi dampak rugi - rugi daya akibat resistansi dari kabel. Data yang telah ditransfer oleh arduino akan diproses oleh aplikasi web, sehingga dapat ditampilkan oleh web browser secara real time. Data yang tertampil pada aplikasi web kemudian disimpan dalam aplikasi ID Tag monitoring.

Rancang bangun sistem gerbang keamanan berbasis RFID ID-12 memperoleh hasil pengujian yang baik dan dapat berfungsi sesuai dengan tujuannya. Tag RFID yang membawa data dapat dipindai oleh reader RFID, kemudian diproses oleh komputer untuk selanjutnya ditampilkan dalam aplikasi web secara real time.
\end{abstract}

Kata kunci: RFID, RFID ID-12, Penguat Kelas C, Antena Eksternal, Aplikasi WEB.

\begin{abstract}
Radio Frequency identification (RFID) is an identification method by using a tool called RFID Tags or transponders to store and retrieve data. RFID technology in securities field can be applied to security gate system at library. Security gate system is designed to detect the incoming and outgoing books from the library and monitored from web application.

Barrier security gate system with RFID ID-12 is built using Arduino. Arduino used to transfer data from RFID reader to computer using serial communication. Additional external antenna used to relocate the electronic device in a safe place. The antenna used together with class $\mathrm{C}$ amplifier, operational class $\mathrm{C}$ amplifier is used to negate the power loss because of resistance from the cable. The data transferred to Arduino and processed using ID tag monitoring, and displayed on web browser in real time. The data displayed on a ID tag monitoring is stored in MySQL database.

Security gate system prototype with RFID ID-12 achieves a good testing result and can function well according to its purpose. RFID Tag data can be scanned by the RFID Reader, then processed by the computer which transferred to the ID tag monitoring in real time.
\end{abstract}

Keyword: RFID, RFID ID-12, Operational Amplifiers C, External antenna, WEB applications. 


\section{PENDAHULUAN}

Teknologi Radio Frequency Identification (RFID) telah dikenal sejak awal perang dunia II. Pada saat itu, RFID digunakan untuk mengindentifikasi antara pesawat musuh dan pesawat sekutu. Sistem tersebut dikenal sebagai Identification Friends or Foe (IFF). Teknologi RFID semakin berkembang dan mulai digunakan dalam berbagai bidang antara lain bidang industri, bidang peternakan, bidang kesehatan dan bidang keamanan.

Teknologi RFID dalam bidang keamanan menarik untuk dikembangkan salah satunya dapat diaplikasikan pada sistem gerbang keamanan perpustakaan. Teknologi ini membantu staf pustakawan dalam hal memeriksa barang-barang yang dipinjam dan lebih meningkatkan keamanan perpustakaan. RFID sendiri adalah kombinasi dari frekuensi radio berbasis teknologi dan teknologi mikrochip yang disebut dengan RFID tag. Kelebihan dari teknologi ini tidak memerlukan kontak langsung saat pembacaan RFID tag oleh RFID reader seperti teknologi barcode dan smart card. Pada pengaplikasiannya gerbang RFID di letakkan pada pintu keluar ruang baca perpustakaan [1].

\section{TINJAUAN PUSTAKA}

\subsection{Radio Frequency Identification (RFID)}

RFID (Radio Frequency Identification) adalah sebuah metode identifikasi data dengan menggunakan tag RFID atau transponder. Tag RFID biasa digunakan sebagai media penyimpanan data pengenal dari suatu obyek. Prinsip kerja dari RFID yaitu dengan menggunakan transmisi frekuensi radio, pada range $125 \mathrm{KHz}, 13.65 \mathrm{MHz}$, atau $800-900 \mathrm{Mhz}$ berdasarkan dari kemampuan RFID itu sendiri. RFID reader berkomunikasi dengan menggunakan gelombang radio secara unik dalam mengidentifikasi obyek. Gambar 1 menerangkan tentang bagaimana cara RFID berkomunikasi.

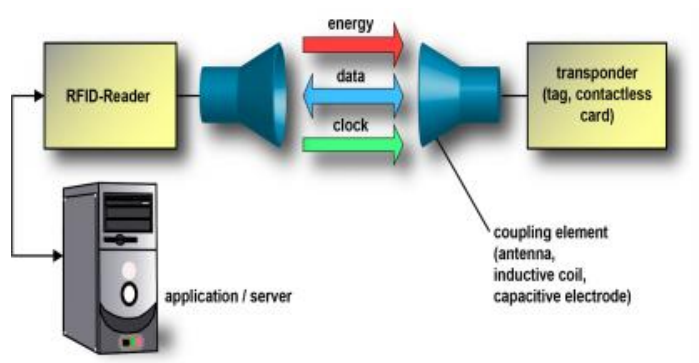

Gambar 1. Prinsip Kerja RFID [1]

Suatu sistem RFID dapat terdiri dari beberapa komponen, seperti tag, reader, tag programming station, circulation reader, sorting equipment dan tongkat inventory tag.

Sistem ini berguna untuk mengirimkan data dari piranti portable, yang dinamakan tag. Tag kemudian dibaca oleh RFID reader dan selanjutnya diproses oleh aplikasi komputer yang membutuhkannya. Data - data yang dibawa oleh tag dapat berisi beragam informasi seperti tanda pengenal suatu obyek, informasi lokasi, harga barang, tanggal kadaluwarsa, dan lain sebagainya [1].

Secara garis besar RFID hanya terbagi menjadi 2 komponen yaitu Tag dan Reader.

\section{Tag RFID}

Tag RFID adalah sebuah microchip berantena yang disertakan pada suatu unit produk. Tag RFID mempunyai suatu komponen inti yaitu inlay. Inlay merupakan komponen yang berisikan chip dimana informasi disimpan. Tag sendiri terbagi menjadi 2 jenis, yaitu:

a. Tag RFID Pasif (Kapasitif)

Tag RFID pasif tidak memiliki power supply sendiri. Dengan berbekal induksi listrik yang ada pada antena yang disebabkan oleh adanya frekuensi radio scanning yang masuk dari terminal RFID. Karena tidak memiliki power supply sendiri maka respon dari suatu label RFID yang pasif biasanya sederhana, hanya nomer ID saja. Tag RFID pasif terdiri dari silicon microprocessor, conductive carbon ink dan paper.

b. Tag RFID Aktif (Induktif)

Tag RFID aktif memiliki power supply sendiri dan memiliki jarak yang lebih jauh dibandingkan dengan tag pasif. 
Memiliki memori yang lebih besar dari tag pasif sehingga dapat menampung berbagai macam informasi didalamnya. Jarak jangkauan dari tag RFID aktif dapat mencapai 100 meter dengan umur baterai yang mencapai beberapa tahun. Tag RFID aktif terdiri dari silicon microprocessor, metal koil dan encapsulating material.

\section{Reader RFID}

RFID reader merupakan sebuah device yang dapat berkomunikasi tanpa kontak langsung dengan tag untuk mengidentifikasinya apabila terhubung dalam suatu asosiasi data. Pada prinsipnya reader memancarkan gelombang radio yang kemudian akan menginduksi tag, selanjutnya tag akan mengirimkan informasi kembali. Reader akan berkomunikasi dengan tag yang memiliki spesifikasi tertentu [1].

\subsubsection{RFID ID-12}

RFID ID-12 hampir sama dengan ID-2 dan ID20 perbedaanya terletak pada antena, ID-12 dan ID-20 mempunyai antena internal dan pin untuk antena eksternal. ID-12 merupakan reader yang khusus mendeteksi RFID tag dengan frekuensi $125 \mathrm{KHz}$, RFID tag yang kompatibel dengan ID12 diantaranya GK4001 dan EM4001 dengan jarak jarak baca $\pm 12 \mathrm{~cm}$. RFID ID-12 mempunyai spesifikasi seperti pada tabel dibawah ini [2].

Tabel 1. Spesifikasi modul RFID ID-12 [2]

\begin{tabular}{|l|l|}
\hline \multicolumn{1}{|c|}{ PARAMETER } & \multicolumn{1}{|c|}{ RFID ID-12 } \\
\hline Jarak Baca & $\pm 12 \mathrm{Cm}$ \\
\hline Dimensi & $26 \mathrm{~mm} \times 25 \mathrm{~mm} \times 7 \mathrm{~mm}$ \\
\hline Frekuensi & $125 \mathrm{KHz}$ \\
\hline Format Kartu & $\begin{array}{l}\text { GK } 4001 / \mathrm{EM} \mathrm{4001} \mathrm{atau} \\
\text { yang compatible }\end{array}$ \\
\hline Encoding & $\begin{array}{l}\text { Manchaster } \\
\text { modulus } 64\end{array}$ \\
\hline Jenis Catudaya & $5 \mathrm{VDC}$ pada $30 \mathrm{~mA}$ nominal \\
\hline Arus I/O & - \\
\hline $\begin{array}{l}\text { Jangkauan } \\
\text { Catudaya }\end{array}$ & $+4.6 \mathrm{~V}-5.4 \mathrm{~V}$ \\
\hline Jaminan Baca & $60 \%$ \\
\hline
\end{tabular}

\subsection{Antena}

Antena adalah sebuah komponen yang dirancang untuk bisa memancarkan dan atau menerima gelombang elektromagnetika. Antena sebagai alat pemancar (transmitting antenna) adalah sebuah transducer (pengubah) elektromagnetis, yang digunakan untuk mengubah gelombang tertuntun di dalam saluran transmisi kabel, menjadi gelombang yang merambat di ruang bebas, dan sebagai alat penerima (receiving antenna) mengubah gelombang ruang bebas menjadi gelombang tertuntun (Gambar 2).

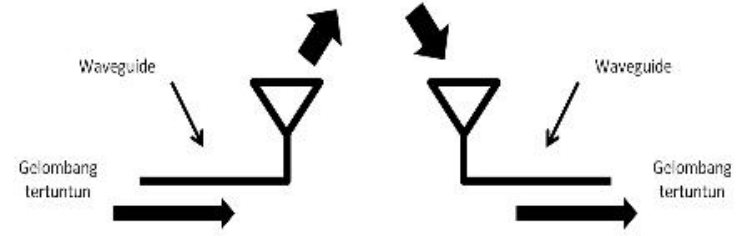

Gambar 2. Peran Antena Di Sistem Komunikasi Nirkabel

Pada sistem komunikasi tanpa kabel yang modern, sebuah antena harus berfungsi sebagai antena yang bisa memancarkan dan menerima gelombang dengan baik untuk suatu arah tertentu [3].

\subsubsection{Antena Eksternal RFID ID-12}

RFID ID-12 mempunyai mempunyai kemampuan membaca pada frekuensi $125 \mathrm{KHz}$, sehingga gain dan diagram radiasi antena reader memainkan peranan penting dalam rancangan sistem RFID. Besar dan bentuk kuantitatif dari keduanya ditentukan oleh aplikasi yang diinginkan, yang menyebabkan berbedanya jangkauan dan wilayah interogasi sistem ini. Antena yang dirancang harus mampu mengkonversi energi yang dikirimkan oleh reader dan meneruskan sinyal yang diterimanya ke reader. Reader harus tetap bisa membaca tag, walaupun tag tersebut diorientasikan secara bebas terhadap reader, artinya tak tergantung pada polarisasi gelombang yang mengenainya. Antena untuk frekuensi sangat rendah (VLF), frekuensi rendah (LF) dan frekuensi menengah (MF) paling tepat menggunakan polarisasi vertikal [3].

Polarisasi linear vertikal bisa dihasilkan dengan antena loop. Antena loop adalah antena yang memiliki jalur sinyal yang terus menerus dari satu konduktor melewati kawat saluran transmisi 
ke konduktor lain. Antena loop memiliki bentuk yang bermacam - macam, seperti lingkaran, persegi, atau persegi panjang. Gambar 3 merupakan contoh bentuk antena loop [4].
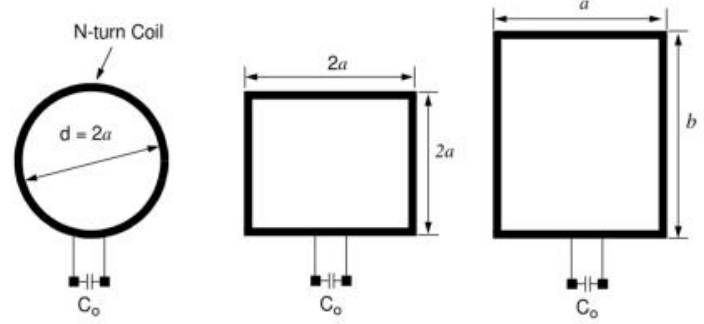

Gambar 3. Bentuk Antena Loop [4]

Antena loop dapat disusun menjadi beberapa loop untuk mendapatkan gain yang lebih besar dan impedansi yang lebih tinggi. Bedasarkan jenisnya, antena loop terbagi menjadi dua, yaitu:

1. Antena loop batang ferit

2. Antena loop air core form (inti udara).

\subsection{Penguat Operasional}

Penguat Operasional atau biasa disebut $O p-A m p$ merupakan suatu jenis penguat elektronika dengan coupling arus searah yang memiliki faktor penguat atau gain sangat besar dengan dua masukan dan satu keluaran. Penguat operasional pada umumnya tersedia dalam bentuk sirkuit terpadu dan yang paling banyak digunakan adalah seri 741 .

Penguat operasional adalah perangkat yang sangat efisien dan serba guna. Contoh penggunaan penguat operasional adalah untuk operasi matematika sederhana seperti penjumlahan dan pengurangan terhadap tegangan listrik hingga dikembangkan kepada penggunaan aplikatif seperti komparator dan osilator dengan distorsi rendah.

Penguat operasional dalam bentuk rangkaian terpadu memiliki karakteristik yang mendekati karakteristik penguat operasional ideal tanpa perlu memperhatikan apa yang terdapat di dalamnya. Karakteristik penguat operasional adalah [5]:

1. Gain tegangan tidak terbatas.

2. Impedansi masukan tidak terbatas.

3. Impedansi keluaran nol.

4. Lebar pita tidak terbatas.

5. Tegangan ofset nol (keluaran akan nol jika masukan nol).

\subsubsection{Penguatan Daya Kelas C}

Penguatan daya kelas $\mathrm{C}$ hanya membutuhkan 1 transistor penguat untuk dapat bekerja dengan baik dan banyak digunakan pada frekuensi di atas $20 \mathrm{KHz}$. Penguatan daya kelas $\mathrm{C}$ didesain khusus untuk menguatkan sinyal hanya 1 fasa positif saja seperti yang diperlukan pada penguatan RFID, frekuensi radio, dll. Tipikal dari rangkaian penguat kelas $\mathrm{C}$ diperlihatkan seperti pada gambar 4 .

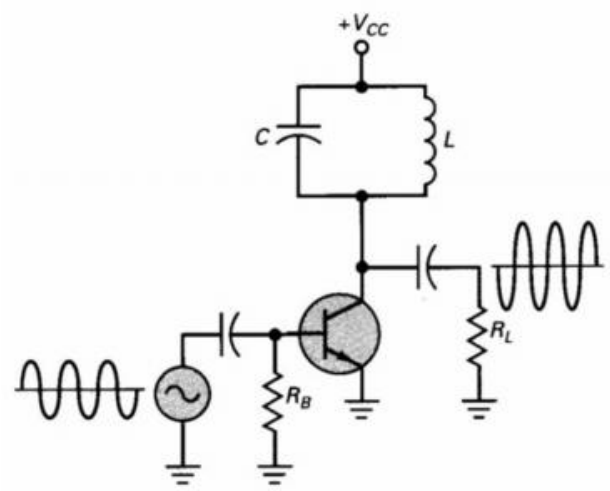

Gambar 4. Rangkaian Penguatan Daya Kelas C [5]

Prinsip kerja penguatan daya kelas $\mathrm{C}$ ialah akan mengaliri arus di kolektor kurang dari $180^{\circ}$ pada setiap siklusnya (tidak sinusoida). Rangkaian penguatan daya kelas $\mathrm{C}$ tidak memerlukan pembuatan bias, karena transistor yang digunakan khusus dirancang bekerja pada daerah saturasi. Rangkaian L-C pada rangakaian tersebut akan beresonansi dan ikut berperan penting dalam mereplika kembali sinyal masukan menjadi sinyal keluaran dengan frekuensi yang sama [5].

\subsection{Arduino dan RFID Shield}

Arduino adalah subuah platform komputasi fisik (Physical Computing) yang open source pada board input output yang sederhana.

Arduino digunakan bersama dengan RFID shield untuk dapat membaca card reader yang melintasinya dan mengirimkannya ke database. Data yang masuk ke database kemudian diolah oleh web aplikasi ID tag monitoring [6]. 


\section{METODE PENELITIAN}

\subsection{Metode Penelitian}

Penelitian dapat diselesaikan dengan melalui beberapa tahapan-tahapan seperti pada Gambar

5.

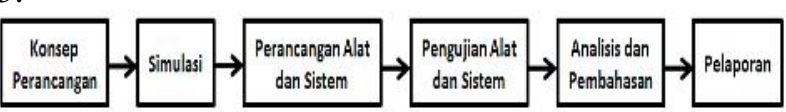

Gambar 5. Tahapan - Tahapan Penelitian

\section{HASIL DAN PEMBAHASAN \\ 4.1. Implementasi Alat}

Realisasi perancangan dari gerbang keamanan yang telah dibuat ditunjukkan pada Gambar 6.

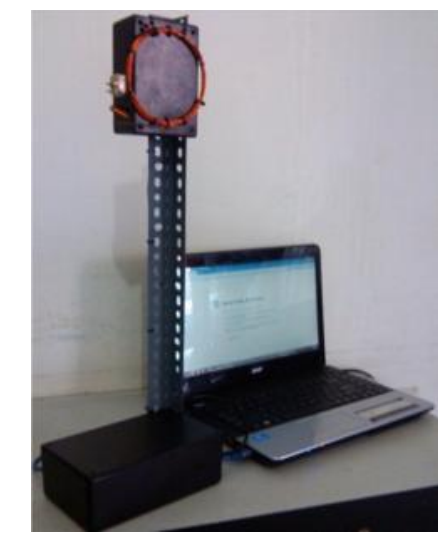

Gambar 6. Bentuk fisik ID Tag

Tampilan aplikasi ID Tag berbasis WEB dapat dilihat pada Gambar 7.

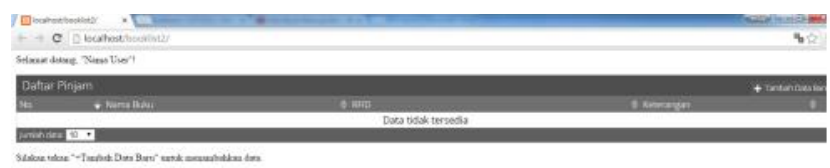

Gambar 7. Tampilan ID Tag pada WEB

\subsection{PENGUJIAN ALAT}

\subsubsection{Pengujian Perangkat Keras}

Pengujian perangkat keras meliputi pengujian RFID, pengujian penguatan operasional dan pengujian antena. Semua pengujian diulang sebanyak 10 kali untuk mendukung akurasi.

\section{A. Pengujian RFID}

RFID berfungsi sebagai sistem yang mengindentifikasi tag RFID ketika akan masuk kedalam perpustakaan. Setiap RFID tag memiliki kode ASCII yang berbeda - beda, nantinya kode tersebut akan diterima oleh mikrokontroler. Adapun pengujian yang dilakukan yaitu pengujian baca RFID, jarak baca, dan pengujian dengan faktor penghambat.

\section{Pengujian Baca RFID}

Pengujian dilakukan dengan memberikan perintah pada mikrokontroler untuk menampilkan kode ASCII yang terdapat pada tag. Tampilan kode ASCII yang diterima dari masing - masing tag saat tag dibaca reader.

\section{COM15 (Arduino Uno)}

49370037DC37B9371B37

$49280028 D C 28 B 9280428$

492B002BDC2BB92B072B

$49340034 D C 34 B 9341834$

4D6006D56CB6556

Gambar 8. Hasil Pembacaan Kode RFID Tag

\section{Pengujian Jarak Baca}

Pengujian dilakukan untuk mengetahui jarak baca yang dapat dijangkau oleh RFID reader. Pengujian dilakukan dengan meletakkan RFID tag tepat diatas RFID reader dengan posisi sejajar. RFID tag didekatkan perlahan - lahan menuju RFID reader dengan cara setiap 1mm RFID tag menuju RFID reader, ditahan selama 2 detik untuk melihat respon apakah RFID tag telah terinduksi oleh antena. Pada Gambar 9 memperlihatkan cara pengujian jarak baca RFID. 


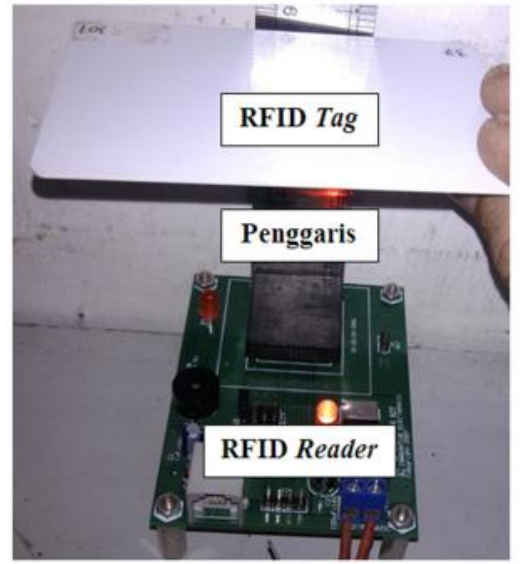

Gambar 9. Pengujian Jarak Baca

Berikut tabel yang menunjukkan jarak baca dari tiap tag.

Tabel 2. Jarak Baca RFID Tag

\begin{tabular}{|c|c|c|}
\hline No & Kode RFID Tag & Jarak Baca \\
\hline 1 & 49370037 DC37B9371B37 & $5.5 \mathrm{~cm}$ \\
\hline 2 & 49280028 DC28B9280428 & $5.5 \mathrm{~cm}$ \\
\hline 3 & $492 \mathrm{~B} 002 \mathrm{BDC}$ BB92B072B & $5.8 \mathrm{~cm}$ \\
\hline 4 & $49340034 \mathrm{DC} 34 \mathrm{~B} 9341834$ & $5.4 \mathrm{~cm}$ \\
\hline 5 & 4D6006D56CB6556 & $5.9 \mathrm{~cm}$ \\
\hline
\end{tabular}

3. Pengujian dengan Faktor Penghalang

Pada pengujian ini diberikan lima kondisi yang berbeda dengan tujuan melihat pengaruh tag dari setiap kondisi. Setiap tag akan dilakukan pengujian dengan dihalangi lima bahan yaitu kayu, plastik, besi, almunium, dan kaca

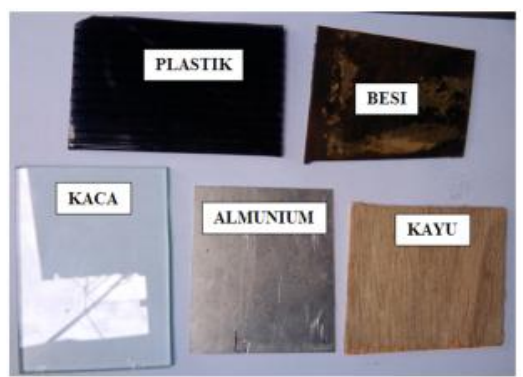

Gambar 10. Lima Faktor Penghalang

Pengujian dilakukan pada jarak $5 \mathrm{~cm}$ dengan ketebalan material yang berbeda dari masing - masing bahan.

Dari hasil pengujian disimpulkan bahwa, RFID Tag tidak dapat terbaca apabila diberikan penghalang besi dan almunium, namun dapat terbaca ketika penghalangnya berupa kayu, kaca, dan plastik.

\section{B. Pengujian Penguatan Daya}

Penguatan daya kelas $\mathrm{C}$ didesain khusus untuk menguatkan sinyal hanya 1 fasa positif saja. Berbeda dengan kelas B yang memerlukan 2 transistor untuk bekerja dengan baik, penguat kelas $\mathrm{C}$ hanya memerlukan 1 transistor. Gambar aplikasi rangkaian penguat daya ditunjukkan pada Gambar 11.

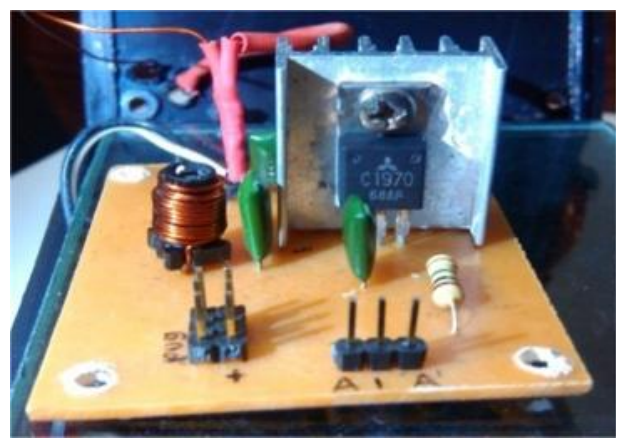

Gambar 11. Aplikasi Rangkaian Penguat Daya

Adapun diagram yang didapat dari oscilloscope, yang diperlihatkan pada Gambar 12.

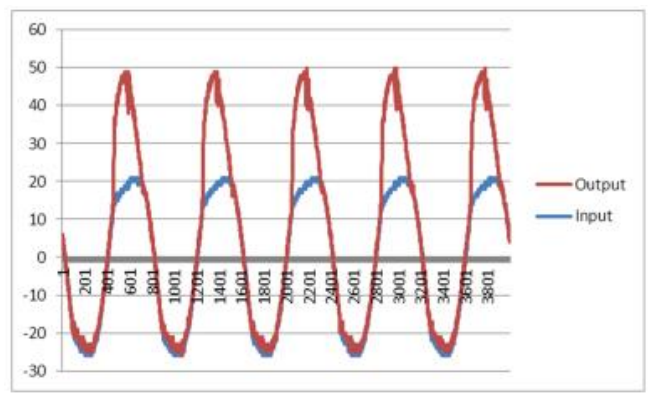

Gambar 12. Hasil Penguatan Daya Kelas C

Pada Gambar 12 dapat dilihat sinyal masukan yang diberikan sebesar $21 \mathrm{mV}$ dan sinyal keluaran sebesar $49 \mathrm{mV}$ dengan frekuensi $125 \mathrm{KHz}$ sehingga daya yang diperoleh $\mathrm{P}_{\text {in }}=$ $0.021 \mathrm{~W}$ dan $\mathrm{P}_{\text {out }}=0.049 \mathrm{~W}$. Maka penguatan yang terjadi sebesar $250 \%$, sedangkan penguatan dalam $\mathrm{dB}$ yang diperoleh sebesar 3.67dB.

Penguat kelas $\mathrm{C}$ menghasilkan keluaran kurang dari $180^{\circ}$ dari sinyal masukan dan hanya memberikan penguatan pada fase positifnya saja. Hal ini karena bias yang diberikan kepada transistor terletak di bawah titik cut-off. 


\section{Pengujian Antena}

Antena loop lingkaran yang telah dirancang dengan spesifikasinya akan dilakukan pengujian. Pengujian antena dilakukan untuk membuktikan bahwa antena telah bekerja pada frekuensi $125 \mathrm{KHz}$.

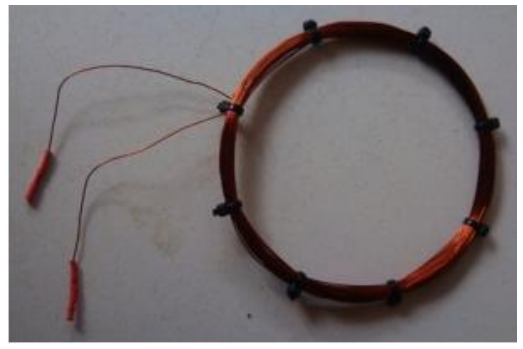

Gambar 13. Antena Eksternal RFID

Gambar 13 merupakan hasil perancangan antena yang telah dibuat. Pengujian dilakukan dengan meletakkan RFID tag tepat diatas RFID reader dengan posisi sejajar. Seperti pada Gambar 14.

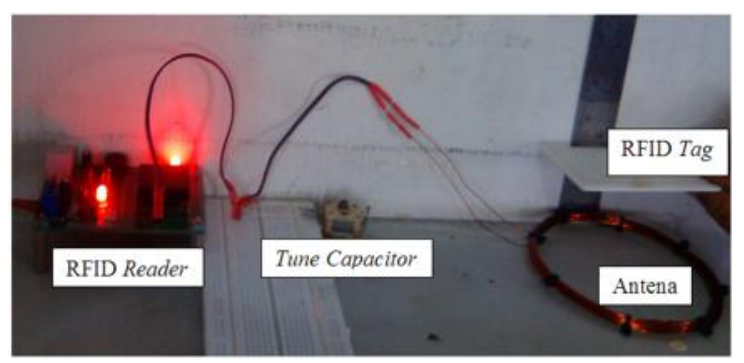

Gambar 14. Pengujian Jarak Baca Antena

Pada Gambar 14 digunakan multimeter analog untuk melihat lonjakan tegangan yang akan menginduktansi tag.

Tabel 3. Hasil Pengujian Jarak Baca Antena Tanpa Penguatan

\begin{tabular}{|c|c|c|}
\hline Kode RFID Tag & Kondisi & $\begin{array}{c}\text { Jarak Baca } \\
\text { Maksimum Antena }\end{array}$ \\
\hline 49370037DC37B9371B37 & Terbaca & $5.5 \mathrm{~cm}$ \\
\hline 49280028DC28B9280428 & Terbaca & $5.5 \mathrm{~cm}$ \\
\hline 492B002BDC2BB92B072B & Terbaca & $5.5 \mathrm{~cm}$ \\
\hline 49340034DC34B9341834 & Terbaca & $5.4 \mathrm{~cm}$ \\
\hline 4D6006D56CB6556 & Terbaca & $5.7 \mathrm{~cm}$ \\
\hline
\end{tabular}

Pada tabel 3 semua tag berhasil dibaca dan tidak ada perbedaan pada jangkauan bacanya. Kabel penghantar berpengaruh terhadap jarak bacanya, semakin panjang kabel penghantar maka semakin besar nilai resistansinya.

\subsubsection{Pengujian Perangkat Lunak}

Pengujian perangkat lunak dilakukan untuk menghasilkan perangkat yang diinginkan dengan pengujian beberapa scenario Fungsionalitas Perangkat Lunak yang telah dibuat.

Hasil pengujian sesuai dan berjalan dengan baik sesuai skenario yang telah dibuat pada Tabel 4 .

Tabel 4. Hasil Pengujian Perangkat Lunak

\begin{tabular}{|c|l|c|}
\hline No & \multicolumn{1}{|c|}{ Skenario } & Hasil \\
\hline 1 & Membaca RFID Tag & Sesuai \\
\hline 2 & Pengiriman data ke Database & Sesuai \\
\hline 3 & Tampilkan data di Aplikasi & Sesuai \\
\hline
\end{tabular}

\subsection{Pengujian Keseluruhan Sistem}

Setelah melakukan pengujian subsistem, tahap selanjutnya adalah melakukan pengujian sistem secara keseluruhan. Pengujian sistem dilakukan untuk mengetahui apakah keseluruhan sistem sudah berjalan sesuai dengan fungsinya.

Berikut tabel 5 menunjukkan kode dari masing masing tag yang akan di uji.

Tabel 5. Kode Tag

\begin{tabular}{|c|c|}
\hline RFID Tag ke- & Kode RFID Tag \\
\hline 1 & 49370037DC37B9371B37 \\
\hline 2 & 49280028DC28B9280428 \\
\hline 3 & 492B002BDC2BB92B072B \\
\hline 4 & 49340034DC34B9341834 \\
\hline 5 & 4D6006D56CB6556 \\
\hline
\end{tabular}

Pada pengujian ini RFID reader yang telah ditambahkan penguatan dan antena akan membaca tag yang melewatinya. Adapun jarak baca yang di peroleh dari rancang bangun ID Tag ini, dapat di lihat pada tabel 6 .

Tabel 6. Jarak baca ID Tag

\begin{tabular}{|c|c|c|c|} 
No. & Kode RFID $\mathrm{Tag}$ & Seljelum Dikuatkan & Setelah Dikuatkan \\
\hline 1. & $49370037 \mathrm{DC} 37 \mathrm{~B} 937 \mathrm{IB} 37$ & $5.5 \mathrm{~cm}$ & $7 \mathrm{~cm}$ \\
\hline 2. & $49280028 \mathrm{DC} 28 \mathrm{~B} 9280428$ & $5.5 \mathrm{~cm}$ & $6.7 \mathrm{~cm}$ \\
\hline 3. & $492 \mathrm{~B} 002 \mathrm{BDC} 2 \mathrm{BB} 92 \mathrm{~B} 072 \mathrm{~B}$ & $5.8 \mathrm{~cm}$ & $6.5 \mathrm{~cm}$ \\
\hline 4. & $49340034 \mathrm{DC} 34 \mathrm{~B} 9341834$ & $5.4 \mathrm{~cm}$ & $6.8 \mathrm{~cm}$ \\
\hline 5. & $4 \mathrm{D} 6006 \mathrm{D} 56 \mathrm{CB} 6556$ & $5.9 \mathrm{~cm}$ & $9.9 \mathrm{~cm}$ \\
\hline
\end{tabular}

Dari tabel 6 menunjukkan jarak baca maksimal diperoleh pada tag 4D6006D56CB6556 dengan jangkauan baca $9.9 \mathrm{~cm}$, sehingga penguatan yang diperoleh sebesar $167 \%$. Penguatan rata rata keseluruhan sistem yang terjadi sebesar $131 \%$. 
RFID Tag yang di scan berhasil terbaca oleh ID Tag dan ditampilkan ke Web Browser dapat dilihat pada Gambar 15.

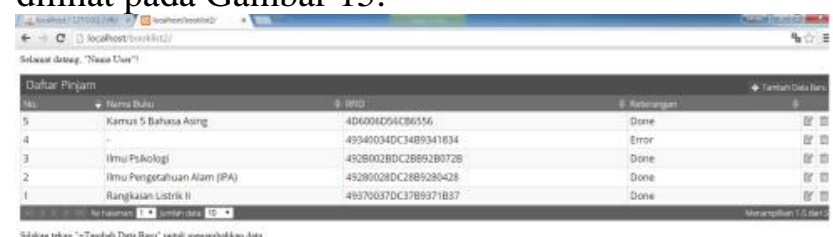

[3] Alaydrus, M. Antena (Prinsip dan Aplikasi). Yogyakarta: Graha ilmu, 2011.

[4] Lee Y. RFID Coil Design. America: Microchip Technology Inc, 2002.

[5] Penguat Operasional, available: http://hyperphysics.phyastr.gsu.edu/hbase/electronic/opamp.html. [Accessed 19 Mei 2015].

[6] Artanto, D. Interaksi Arduino dan

Labview. Jakarta: Elex Media

Komputindo, 2012.

Gambar 15. Tampilan ID Tag

Tag yang berhasil terbaca dan terdapat pada database akan diberikan keterangan done, sedangkan yang tidak ada pada database diberikan keterangan error.

\section{KESIMPULAN}

Berdasarkan hasil dan analisis yang telah dilakukan, ada beberapa hal yang dapat disimpulkan diantaranya yaitu:

1. Telah terbuat rancangan sistem gerbang keamanan pada perpustakaan dengan menggunakan RFID.

2. Telah terbangun antena pemindai RFID pada lokasi yang berbeda dari perangkat elektronik pengolah data.

3. Sistem gerbang keamanan dapat diakses melalui aplikasi web yang membaca RFID dan melakukan komparasi dengan database.

4. Antena eksternal RFID dengan penguatan kelas $\mathrm{C}$ mengalami peningkatan jarak baca rata - rata sebesar $131 \%$.

\section{DAFTAR PUSTAKA}

[1] Nadhir, I. Rancang Bangun Model Garasi dengan Aplikasi RFID Berbasis Mikrokontroler. Bandar Lampung:

Universitas Lampung, 2014.

[2] RFID ID-12 datasheet, available: https://www.sparkfun.com/datasheets/Sen sors/ID-12-Datasheet.pdf. [Accessed 15 Januari 2014]. 